\title{
Editorial
}

\section{Introduction to the Special Issue on Emergency Telecommunications via Satellites}

\author{
GUEST EDITORS: Matteo Berioli ${ }^{1}$ and Laurent Franck $^{2, *, \dagger}$ \\ ${ }^{1}$ Deutsches Zentrum für Luft-und Raumfahrt (DLR),Weßling, Germany \\ ${ }^{2}$ Télécom Bretagne, Toulouse, France
}

Every year, we are reminded about the challenges of disaster management when a catastrophe strikes and makes thousands of casualties. Every year, we are experiencing the frustrating feeling that coping effectively with disaster management is a never-ending story and that everything has still to be done.

This is obviously inaccurate but it reflects the complexity of the topic. Among the various factors that make disaster management so challenging and each situation unique, let us highlight a few of them:

- Disasters strike anywhere, anytime but call for a fast response;

- The transport, power and telecommunication infrastructures are often impaired if not destroyed;

- Disaster management implies the co-operation of various organisations and authorities from different countries;

- The sovereignty and laws of country where the disaster takes place must not be infringed despite the gravity of the situation.

In this context, it is not surprising that the first hours or days after the disaster are chaotic. One important tool to work against the ramping entropy is telecommunications and one might notice that on the first hours after the disaster, the media teams are the one likely to be equipped with the most powerful telecommunications means.

Indeed, media teams face similar challenges: transmitting data from anywhere at anytime without a priori knowledge of available telecommunications facilities. Satellites offer missioncritical services to them. This leads us to two conclusions: (a) satellite technology deserves a specific care when addressing emergency telecommunications and (b) the satellite technologies to be used and the way they should be used is not straightforward.

This special issue is about satellite communications and how they contribute to effective and efficient disaster management. We believe that devising emergency communication networks is still a many fold open issue. Although economic and political aspects are major locks to mitigate, there are several heterogeneous aspects to be faced (use of backhauling, use of messaging services, distribution of earth observation data, efficient resource management, location-based services, etc.) and also for each aspect different technical issues calling for ad hoc solutions. The articles presented here address inevitably only a subset of all possible issues, but they present interesting novel solutions for key problems in the area, proving again (if ever it

*Correspondence to: L. Franck, Télécom Bretagne, Toulouse, France.

${ }^{\dagger}$ E-mail: Laurent.Franck@telecom-bretagne.eu 
was needed) the importance of satellite communications in this scenario, and reflecting very well the heterogeneity and broadness of the topic.

The first paper of this special issue with authors from the Industry (manufacturers and operators) and the Academy provides an overview of the roles and challenges of satellite communications applied to disaster management [1].

Rajeev Gopal, in the second paper of the issue, shows the advantages available when a multibeam regenerative meshed satellite network is used to provide telecommunications services in case of emergency; the main reference here is the American geostationary satellite system based on Spaceway-3, developed by Hughes Network Systems, which entered into service in 2008. Classical transparent satellite systems always rely on a terrestrial hub to manage the network, terminalto-terminal communications with a single satellite hop (transparent meshed systems) are quite complex and inefficient (terminals can be assigned to specific fix-sized carriers to communicate) and in any case only possible with the signalling support of a terrestrial network control centre [2]. The on-board switching and the on-board bandwidth-on-demand (BoD) and dynamic resources management available in the system proposed in this article make possible: (a) a very efficient resource management, which can face the unpredictable, and normally very high, demand in a disaster situation; (b) intra-disaster area connectivity with single satellite hop, even if the disaster area is larger than a satellite spot beam; (c) the quick set-up of a new satellite network without relying on any terrestrial infrastructure, which may always be affected by the disaster.

The third paper presents the results of the project WISECOM, financed by the European Commission on the 6th Framework Programme, and the paper is edited by Matteo Berioli with the contributions of all project partners [3]. WISECOM was proposed as an after-disaster solution for the quick deployment of a system for satellite backhauling of $3 \mathrm{G}$ and $4 \mathrm{G}$ wireless terrestrial technologies, and it has become in the last years an archetypical approach for fast recovery of communication infrastructures destroyed by a disaster. By using a lightweight satellite terminal (such as Inmarsat BGAN), it is possible to establish a satellite connection in a few minutes and to provide enough backhauling resources to set-up a local $3 \mathrm{G} / 4 \mathrm{G}$ cell of a few hundreds-meters radius on the disaster area. Then, during the disaster recovery phase (a few hours or days after the first disaster strike), the lightweight satellite antenna can be replaced with a more directive one; this enables the use of broadband satellite terminals (e.g. DVB-RCS) and, as a consequence, the possibility to have more powerful $3 \mathrm{G} / 4 \mathrm{G}$ local base stations (with coverage of a few kilometres). This idea results in an efficient two-phase approach when restoring communications after a disaster. The paper also presents some results of a demonstration campaign held with a prototype of the system.

The fourth paper, written by Lewandowski et al., addresses the problem of satellite-based Search-and-Rescue (SAR) services. SAR services are meant as the capability of detecting a distress alert message from a user anywhere in the world and as the possibility to distribute back to the alerting device some information data (e.g. at least the acknowledgement of alert reception) [4]. A satellite SAR system, named Cospas-Sarsat, is currently in service; it was established by Canada, France, the United States, and Russia in 1979. It is also being planned to equip some satellites of the European satellite navigation system Galileo with some SAR communications devices in order to extend the Cospas-Sarsat and to provide an enhanced worldwide SAR service. The key parameter to be considered for this SAR service is the time needed for a sender anywhere in the world to deliver its alert message to a global rescue coordination centre. The paper investigates all these issues, it proposes a SAR Short Messaging Service (SMS) to improve the process of alert retrieval by providing more information from the incident scene, and it finally derives the minimum number of Galileo satellites carrying SAR payload to guarantee a worldwide average delivery time for the alerting messages.

The fifth and last paper entitled 'A Novel Hybrid Algorithm for Passive Localization of Victims in Emergency Situations' from Dimitri Tassetto et al. discusses the localization of victims after disasters, such as a landslide, avalanche or earthquake [5]. During these events, response time is critical and SAR resources are scarce. The authors propose the extension of the Wisecom Access Terminal (WAT) - a multi-technology equipment providing emergency communication backhauling via satellite - in order to locate active GSM terminals in the 
disaster zone. The use of unmodified GSM terminals as passive emergency beacons is an interesting development and the implementation in the WAT makes it possible to substitute to a destroyed GSM infrastructure.

To conclude, we thank the reviewers for their time spent in carefully evaluating the nine papers that we received. We hope that - as we did-you will appreciate reading these contributions and that through them you will sense the many challenges the satellite community is facing.

Indeed, the topic raises a difficult question: how to devise next generation telecommunications systems that are technically and economically viable in an environment where even the word market has to be re-coined. We are convinced that satellite communications because of their global and versatile features have to play a primary role.

\section{REFERENCES}

1. Franck L, Berioli M, Boutry P, Harles G, Ronga LS, Suffritti R, Thomasson L. On the role of satellite communications for emergency situations with a focus on Europe. International Journal of Satellite Communications and Networking, DOI: 10.1002/sat.979.

2. Gopal R. Net-centric satellite mesh architecture for emergency communication. International Journal of Satellite Communications and Networking, DOI: 10.1002/sat.981.

3. Berioli M, Chaves JM, Courville N, Boutry P, Fondere J-L, Skinnemoen H, Tork H, Werner M, Weinlich M. WISECOM: A rapidly deployable satellite backhauling system for emergency situations. International Journal of Satellite Communications and Networking, DOI: 10.1002/sat.982.

4. Lewandowski A, Niehoefer B, Wietfeld C. Galileo/SAR: Performance aspects and new service capabilities. International Journal of Satellite Communications and Networking, DOI: 10.1002/sat.983.

5. Tassetto D, Fazli EH, Werner M. A novel hybrid algorithm for passive localization of victims in emergency situations. International Journal of Satellite Communications and Networking, DOI: 10.1002/sat.984.

\section{AUTHORS’ BIOGRAPHIES}

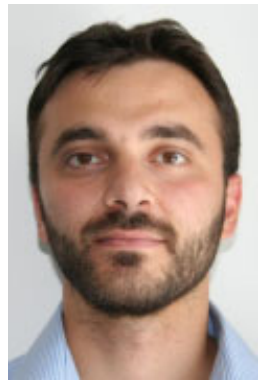

Matteo Berioli received a Laurea degree in electronic engineering, and the $\mathrm{PhD}$ degree in information engineering from the University of Perugia (Italy), both with honors, in 2001 and 2005 respectively. Since 2002 he is with the German Aerospace Center (DLR), where since 2008 he is leading the Networking and Protocols Group of the Digital Networks Department in the Institute of Communications and Navigation. His main research activities are in the area of IP-based satellite networks; key research issues include QoS and protocol analysis, cross-layer techniques and packet-layer coding. Since 2006 he also works as an expert for the European Telecommunications Standards Institute (ETSI) in the area of broadband satellite multimedia; he has been the chairman of the satellite working group of the PSCE Forum (Public Safety Communications Europe Forum). Matteo Berioli is author/co-author of around 50 papers that appeared in international journals and conference proceedings. Matteo Berioli was the general project manager of the WISECOM project, and he has been working in several European (EU and ESA) research projects with leading roles, often coordinating technical activities and satellite system life trials.

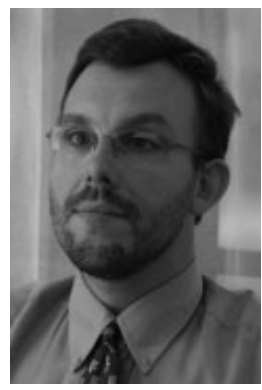

Laurent Franck has a PhD degree in telecommunications from Telecom ParisTech in 2001. Since 2007 he is with Telecom Bretagne (Toulouse site) where he teaches and conducts research on satellite networking. His main research interests are in the development of satellite-based emergency communications. Laurent is also a volunteer first-aid worker for the French Red Cross. 